\title{
PREVALENCE OF VISCERAL LEISHMANIASIS, RISK FACTORS AND ASSOCIATED DISORDERS: KNOWLEDGE OF INHABITANTS AND PROFESSIONALS IN FULBARIA, MYMENSINGH
}

\author{
Anindita Rani Bhowmick and Hamida Khanum* \\ Department of Zoology, University of Dhaka, Dhaka-1000, Bangladesh
}

\begin{abstract}
A total of 215 cases were recorded from the rural areas of Fulbaria upazila during June 2015 to May 2016. The prevalence of kala-azar was higher in male $(51.22 \%)$ than female $(36.96 \%)$. In the area, 10.1 - 20 years age group was the most prevalent group and the prevalence was found to decrease with the increase of age. Post Kala-azar Dermal Leishmaniasis (PKDL) was developed in $38.14 \%$ of kala-azar patients of Fulbaria upazila. The prevalence of kala-azar was found $63.89 \%$ in mud house dwellers and when living in tin shed house but with earthen floor, the prevalence was $58.79 \%$. On the other hand, $10.31 \%$ had single infection with kala-azar, $21.65 \%$ had double infection and $68.04 \%$ had multiple infection. Living in proximity to prior case, climatic change, racked mud house, humid area, cattle sheds made of cracked mud walls, lack of awareness and knowledge regarding kala azar were the risk factors. Total 45 professionals were interviewed in the Upazila Health Complex and Upazila Sub-Centers of the study area through a preset questionnaire. Of them, $71.11 \%$ had the appropriate acquaintance about the agent (Leishmania donovani) of kala-azar and $35.29 \%$ professionals had the correct comprehension regarding the reservoir of kala-azar (man). Most of them (91.11\%) recommended rK 39 dipstick test as the single most important diagnostic blood test and Miltefosine and Amphotericin B are the most recommended drugs for treatment of kala-azar.
\end{abstract}

Key words: Visceral leishmaniasis, risk factors, associated disorders.

\section{INTRODUCTION}

Visceral leishmaniasis (VL), also known as kala-azar (KA), is a major public health problem in Bangladesh, India and Nepal. The word "kala-azar" has been derived from two Indian words "kala" and "azar" meaning "Black sickness"- an illness in which the colour (pigmentation) of the body turns black. The word "kala" also means "deadly", thereby signifying a fatal illness (Chatterjee 1995). VL is the world's second-deadliest parasitic disease after malaria, with 400,000 cases and 40,000 deaths occurring annually (Alvar et al. 2006). VL is a neglected tropical disease transmitted by sandflies (Le Rutte et al. 2016). The disease burden is highest in India, followed by Bangladesh and Nepal. Out of 64

*Author for correspondence: <hamida_khanum@yahoo.com>

(C) 2017 Zoological Society of Bangladesh DOI: http://dx.doi.org/10.3329/bjz.v45i1.34197 
districts of Bangladesh, 45 are endemic for VL and 20 million people, around $18 \%$ of the total population, are considered to be at risk for VL. Without treatment, VL is nearly always fatal (Alvar et al. 2012). The disease is caused by a parasite called Leishmania and is transmitted by the bite of female sandfly, Phlebotomus argentipes (Park and Park 1987). Kala-azar is a disease of reticuloendnothelial system (RES), characterized by chronic fever, substantial weight loss, enlargement of the spleen and liver, anaemia and depletion of platelets in the blood.

The disease usually affects the poorest population living in remote rural areas. Poor housing and sanitary conditions create an ideal breeding ground for sandflies and at the same time, chronic health conditions such as malnutrition lower the ability of at-risk individuals to resist the disease. Sandfly may obtain the parasite directly from the infected skin or by ingesting the parasite from the circulating blood of the reservoir host. (Park and Park 1987). A major challenge towards VL elimination is the rising incidence of PKDL which occurs after the VL treatment and act as an infection reservoir, threatens the VL elimination initiative. PKDL is a skin disorder which usually develops in 10-20\% and about $60 \%$ of patients with visceral leishmaniasis (VL) after treatment respectively in the Indian subcontinent and Sudan. These patients are difficult to diagnose and treat, as some of them may not have even past history of VL (Rahman et al. 2010).

The elimination campaign has been running in the Indian subcontinent (India, Nepal, Bangladesh, Bhutan and Thailand) since 2005 (WHO 2015). On the Indian subcontinent, the target is to eliminate VL as a public health problem by or before the end of 2017, where elimination is defined as an annual incidence of VL of $<1$ per 10,000 capita at sub-district-levels in Bangladesh and India and at district-levels in Bhutan and Nepal. In the rest of the world, the WHO target is $100 \%$ detection and treatment of all VL cases.

\section{MATERIAL AND METHODS}

Study areas and period: The present study was conducted in rural areas of Fulbaria upazila (endemic area) of Mymensingh district. Seven unions of Fulbaria upazila were selected. These were Fulbaria, Kushmail, Putijana, Radhakanai, Bakta, Balian and Kaladaha. The study was conducted from June 2015 to May 2016.

Sample scheme: Total 215 inhabitants and 45 professionals were interviewed in the study areas. The observed inhabitants were divided into two sex groupsmale and female. They were divided into seven age groups for analysis. Data was collected about the education, occupation, house type, presence of cattle shed, 
presence of chicken/pigeon shed, blood group etc from the study areas. Investigation on knowledge, attitude and practice of inhabitants and professionals for treatment, prevention and control of visceral leishmaniasis was carried out.

Procedure of data collection: Data was recorded through a preset questionnaire. Data collection was done from the inhabitants and households and from professionals in the Upazila Health Complex and Upazila Sub-Centres in the study areas. Demographic and socio-economic conditions of the households was also observed. The data of the treated patients were also collected from Upazila Health Complex.

\section{RESULTS AND DISCUSSION}

A total of 215 suspected inhabitants were interviewed for visceral leishmaniasis (VL) from the rural areas of 7 unions of Fulbaria upazila, Mymensingh district. In the present study, total 85 professionals were interviewed in the Upazila Health Complex and Upazila Sub-Centers of Fulbaria upazila. In Fulbaria upazila, out of 215 inhabitants, kala-azar patients were 97 in number and the overall prevalence of kala-azar patients was $45.12 \%$. The prevalence of kala-azar in male was $51.22 \%$ and in female was $36.96 \%$ (Fig. 1). The result was consistent with the study findings of ICDDR, B (2003).

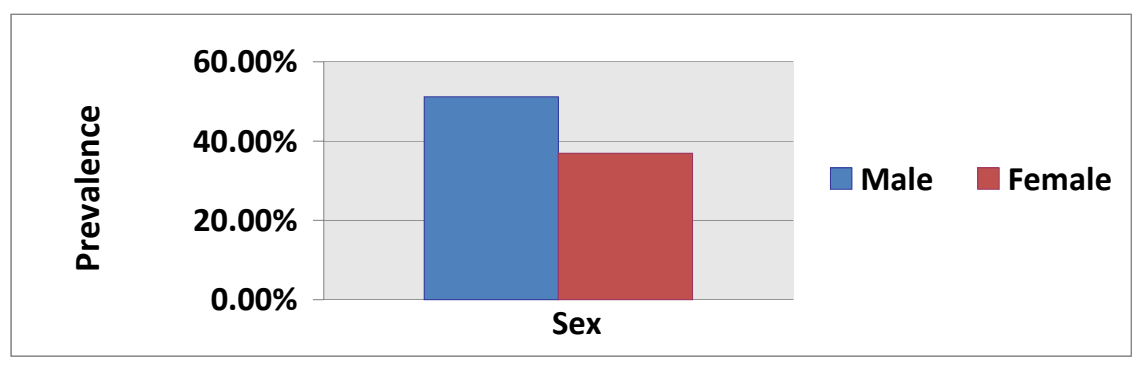

Fig. 1. Prevalence of kala-azar in male and female inhabitants in Fulbaria upazila.

The highest prevalence of kala-azar patients was found in 10.1 - 20 years age group (67.35\%) and the lowest prevalence was found in 60-above age group $(8.33 \%)$. The prevalence of KA showed a decreased value with the increase of age (Table 1). In Bangladesh, the maximum numbers of cases were reported in the age group of $11-20$ years (Thakur 1984). This is probably because of low immunity and lower prevalence of protective delayed type hepersensitivity (DTH) responses in young than adult. 
In the present study, the prevalence of VL was observed in different seasons. The highest prevalence (59.34\%) of VL patients was found during the summer season and the next prevalence (44.29\%) was found in the rainy season. The winter season had the lowest prevalence (22.22\%) (Table 2).

Table 1. Prevalence of kala-azar in inhabitants of different age groups in Fulbaria upazila

\begin{tabular}{lccc}
\hline $\begin{array}{l}\text { Age } \\
\text { group }\end{array}$ & $\begin{array}{c}\text { Total } \\
\text { observation }\end{array}$ & $\begin{array}{c}\text { Number of kala-azar } \\
\text { patients }\end{array}$ & $\begin{array}{c}\text { Prevalence of kala-azar } \\
\text { patiens (\%) }\end{array}$ \\
\hline $0.1-10$ & 30 & 13 & 43.33 \\
$10.1-20$ & 49 & 33 & 67.35 \\
$20.1-30$ & 47 & 27 & 57.45 \\
$30.1-40$ & 19 & 9 & 47.37 \\
$40.1-50$ & 21 & 6 & 28.57 \\
$50.1-60$ & 25 & 7 & 28.00 \\
Above 60 & 24 & 2 & 8.33 \\
\hline
\end{tabular}

Table 2. Prevalence of kala-azar in different seasons in the study area

\begin{tabular}{lccc}
\hline Season & $\begin{array}{c}\text { Total } \\
\text { observation }\end{array}$ & $\begin{array}{c}\text { Number of kala- } \\
\text { azar patients }\end{array}$ & $\begin{array}{c}\text { Prevalence of kala- } \\
\text { azar patients (\%) }\end{array}$ \\
\hline Rainy (July-October) & 70 & 31 & 44.29 \\
Winter (November-February) & 54 & 12 & 22.22 \\
Summer (March-June) & 91 & 54 & 59.34 \\
\hline
\end{tabular}

In the study area, out of 97 kala-azar patients, 10 patients $(10.31 \%)$ had single infection with leishmaniasis; 21 patients $(21.65 \%)$ had double infection and 66 patients $(68.04 \%)$ had multiple infections infecting with jaundice, ascitis, anaemia, oedema, hepatomegaly, splenomegaly etc. (Fig. 2). Post Kala-azar Dermal Leishmaniasis (PKDL) was found to occur in case of many kala-azar patients. In Fulbaria upazila, 37 PKDL cases were found out of 97 kala-azar patients and the prevalence of PKDL positive cases was $38.14 \%$ (Table 3). Bern and Chowdhury (2006) specified that ascertainment and treatment of PKDL patients would become a key issue for the control programme, especially when kala-azar incidence rates fall.

In Fulbaria upazila, the highest prevalence of kala-azar patients was found in blood group $\mathrm{B}+(71.11 \%)$. The other prevalences of kala-azar patients were $34.21 \%$ in blood group $\mathrm{A}+, 56.00 \%$ in blood group $\mathrm{AB}+, 14.29 \%$ in blood group B-, $14.29 \%$ in blood group AB- and $52.17 \%$ in O+ (Fig. 3). A study by Evans 
et al. (1984) indicated that $\mathrm{ABO}$ blood group type is not an important determinant in the development of clinically apparent visceral leishmaniasis.

The highest prevalence was found in case of agriculture farmers (68.42\%) and a higher prevalence was also found in case of housewives (45.90) and labour (43.75). No patient was found in case of service-holders (Table 4).

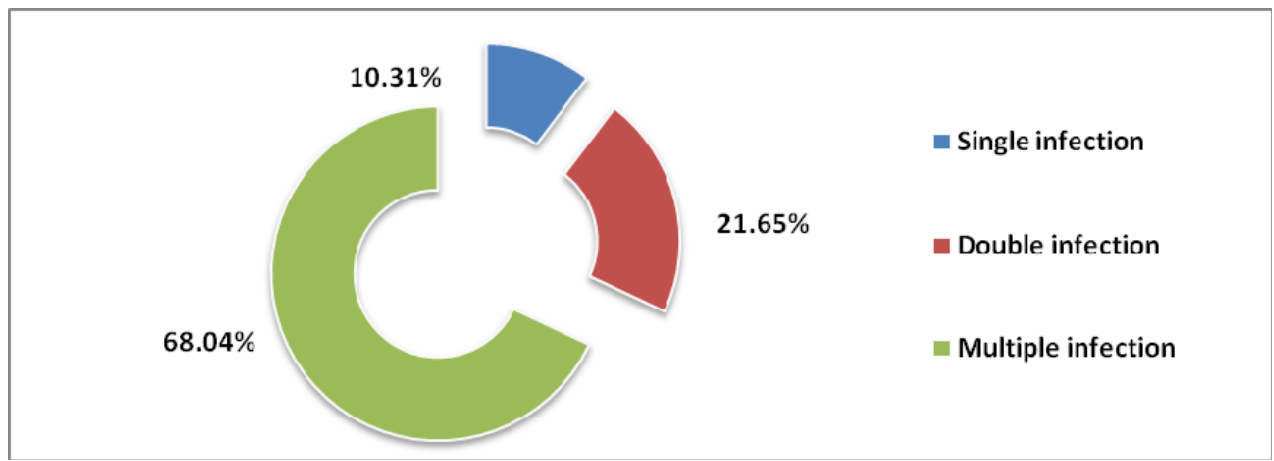

Fig. 2. Prevalence of associated disorders in kala-azar patients in Fulbaria upazila.

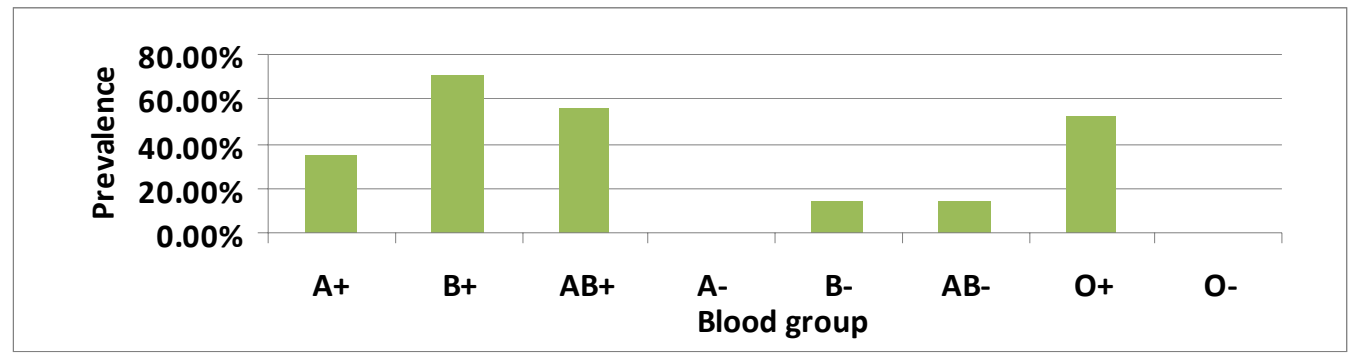

Fig. 3. Prevalence of kala-azar in inhabitants of different blood groups in Fulbaria upazila.

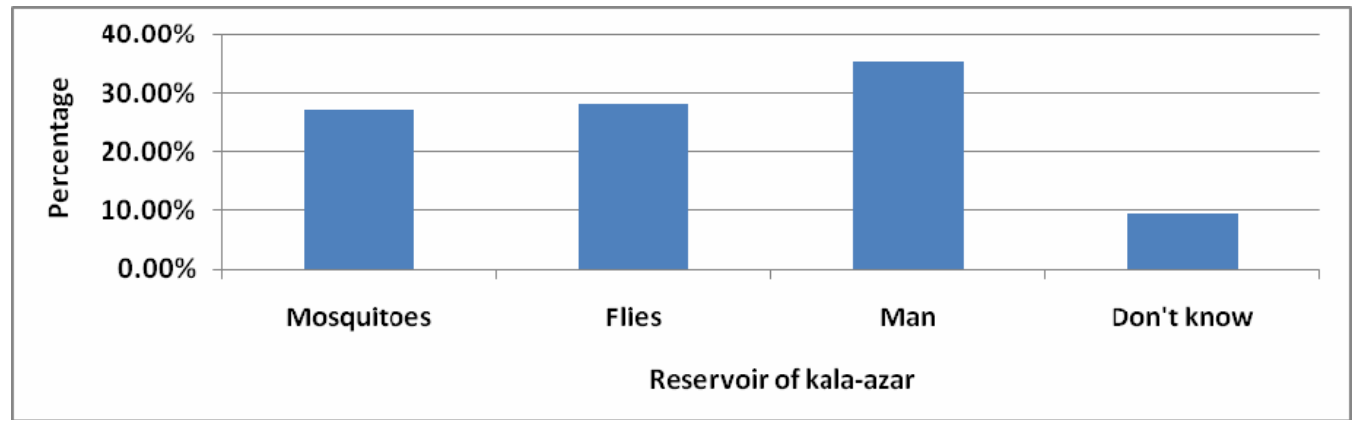

Fig. 4. Knowledge of the professionals regarding the reservoir of kala-azar. 
The highest prevalence (63.89\%) was found in mud house dwellers. A higher prevalence $(58.79 \%)$ was also found in residents of houses made of tin wall and mud floor. No patient was found in houses made of brick wall and concrete floor (Table 5). Ranjan et al. (2005) showed in a study that the use of mud for wall construction or for plastering walls was found to be significantly associated with kala-azar.

Table 3. Prevalence of PKDL among the kala-azar patients in the study area

\begin{tabular}{ccc}
\hline $\begin{array}{c}\text { Total number of kala-azar } \\
\text { patients observed }\end{array}$ & $\begin{array}{c}\text { Number of PKDL } \\
\text { positive cases }\end{array}$ & $\begin{array}{c}\text { Prevalence of PKDL } \\
\text { positive cases (\%) }\end{array}$ \\
\hline 97 & 37 & 38.14 \\
\hline
\end{tabular}

Table 4. Prevalence of kala-azar in inhabitants of different occupations in the study area

\begin{tabular}{lccc}
\hline Occupation & $\begin{array}{c}\text { Total } \\
\text { observation }\end{array}$ & $\begin{array}{c}\text { Number of kala-azar } \\
\text { patients }\end{array}$ & $\begin{array}{c}\text { Prevalence of kala-azar } \\
\text { patients (\%) }\end{array}$ \\
\hline Agriculture & 57 & 39 & 68.42 \\
Business & 26 & 7 & 26.92 \\
Housewife & 61 & 28 & 45.90 \\
Service & 9 & 0 & 0 \\
Labour & 16 & 7 & 43.75 \\
Student & 27 & 9 & 33.33 \\
Others & 19 & 7 & 36.84 \\
\hline
\end{tabular}

Table 5. Prevalence of kala-azar in inhabitants of different types of houses in the study area

\begin{tabular}{lccc}
\hline $\begin{array}{l}\text { Type of } \\
\text { house }\end{array}$ & $\begin{array}{c}\text { Total number } \\
\text { of observed } \\
\text { inhabitants }\end{array}$ & $\begin{array}{c}\text { Number of } \\
\text { kala-azar cases }\end{array}$ & $\begin{array}{c}\text { Prevalence of kala- } \\
\text { azar in particular } \\
\text { type of house (\%) }\end{array}$ \\
\hline Mud wall and mud floor & 72 & 46 & 63.89 \\
Tin wall and mud floor & 165 & 97 & 58.79 \\
Tin wall and concrete floor & 83 & 15 & 18.07 \\
Brick wall and concrete floor & 39 & 0 & 0 \\
\hline
\end{tabular}

In Fulbaria, total 94 patients out of 97 kala-azar patients had cattle shed in their houses and the prevalence was $96.91 \%$. Total 89 patients had chicken/pigeon shed in their houses out of 97 kala-azar patients and the prevalence was 93.44\% (Table 6). Yared et al. (2014) reported in a study that 
animal ownership such as presence of cattle, owning dogs, goats and owning donkeys were found to significantly increase the odds of VL.

The respondents were asked some questions about various aspects of kalaazar through a questionnaire. It was found that all of the observed 215 respondents heard about kala-azar (100\%) and 171 respondents $(79.53 \%)$ heard of any of kala-azar cases in or around their houses. $90.23 \%$ respondents believed that kala-azar spreads from sick person to another and $37.67 \%$ believed that kala-azar is not curable. $99.07 \%$ respondents answered that they had not heard about sand fly (Table 7).

Table 6. Prevalence of kala-azar patients having cattle shed and chicken/pigeon shed in houses in the study area

\begin{tabular}{lcc}
\hline Animal shed & $\begin{array}{c}\text { Number of KA patients having } \\
\text { animal shed (total KA patients } \\
97)\end{array}$ & $\begin{array}{c}\text { Prevalence of KA patients } \\
\text { having animal shed (\%) }\end{array}$ \\
\hline Cattle shed & 94 & 96.91 \\
Chicken/pigeon shed & 89 & 93.44 \\
\hline
\end{tabular}

Table 7. Knowledge of inhabitants regarding some aspects of kala-azar in the study area

\begin{tabular}{|c|c|c|c|c|c|c|}
\hline \multirow[b]{2}{*}{ Question } & \multicolumn{6}{|c|}{ Answer of inhabitants (total 215) } \\
\hline & Yes & $\%$ & No & $\%$ & $\begin{array}{l}\text { Don't } \\
\text { know }\end{array}$ & $\%$ \\
\hline $\begin{array}{l}\text { Have you heard the name of } \\
\text { kala-azar? }\end{array}$ & 215 & 100 & - & - & - & - \\
\hline $\begin{array}{l}\text { Have you heard of any of kala- } \\
\text { azar cases in or around your } \\
\text { house? }\end{array}$ & 171 & 79.53 & 41 & 19.07 & 3 & 1.40 \\
\hline $\begin{array}{l}\text { Do you think kala-azar spread } \\
\text { from sick person to another? }\end{array}$ & 194 & 90.23 & 12 & 5.58 & 9 & 4.19 \\
\hline $\begin{array}{l}\text { Do you know kala-azar is } \\
\text { curable? }\end{array}$ & 114 & 53.02 & 81 & 37.67 & 20 & 9.30 \\
\hline Have you heard about sand fly? & 2 & 0.93 & 213 & 99.07 & - & - \\
\hline
\end{tabular}

Total 45 professionals were interviewed in the study areas. Among them, $71.11 \%$ professionals had the correct knowledge regarding the specific agent (Leishmania donovani) of kala-azar while $15.56 \%$ professionals believed Entamoeba histolytica and $8.89 \%$ professionals believed Wuchereria bancrofti as the specific agent of kala-azar and $4.44 \%$ professionals did not know which is the agent of the disease (Table 8).

Khanum and Akhter (2008) reported that among the professionals, about $80.4 \%$ had the correct knowledge regarding the specific agent (Leishmania donovani) of kala-azar, $9.8 \%$ did not have clear conception and $5.4 \%$ of the said 
Plasmodium falciparum and 3.3\% said Wuchereria bancroft is the specific agent of the disease. It was observed that, 35.29\% professionals had the correct knowledge regarding the reservoir of kala-azar (man) and $27.06 \%$ professionals believed that mosquitoes are the reservoir of kala-azar (Fig. 4).

Table 8. Knowledge of the professionals regarding the agent of kala-azar

\begin{tabular}{lcccccccc}
\hline \multirow{2}{*}{$\begin{array}{l}\text { Agent of } \\
\text { kala-azar }\end{array}$} & \multicolumn{4}{c}{ Designation/job details } & \multicolumn{3}{c}{ Total \% } \\
\cline { 2 - 7 } & RMO & MO & Nurse & SACMO & $\begin{array}{c}\text { MA- } \\
\text { UHC }\end{array}$ & $\begin{array}{c}\text { MA-USC/ } \\
\text { UHFWC }\end{array}$ & \\
\hline $\begin{array}{l}\text { Leishmania } \\
\text { donovani }\end{array}$ & 1 & 21 & 5 & - & 2 & 3 & 32 & 71.11 \\
$\begin{array}{l}\text { Entamoeba } \\
\text { histolytica }\end{array}$ & - & & 2 & 1 & 2 & 2 & 7 & 15.56 \\
$\begin{array}{l}\text { Wuchereria } \\
\text { bancrofti }\end{array}$ & - & - & 2 & - & - & 2 & 4 & 8.89 \\
$\begin{array}{l}\text { Do not know } \\
\text { Total }\end{array}$ & - & - & & 1 & 1 & - & 2 & 4.44 \\
\hline
\end{tabular}

$\mathrm{RMO}=$ Resident Medical Officer, $\mathrm{MO}=$ Medical Officer, SACMO $=$ Sub-Assistant Community Medical Officer, MA-UHC = Medical Assistant-Upazila Health Complex, MAUSC/UHFWC = Medical Assistant-Union Sub-Center / Union Health and Family Welfare Center.

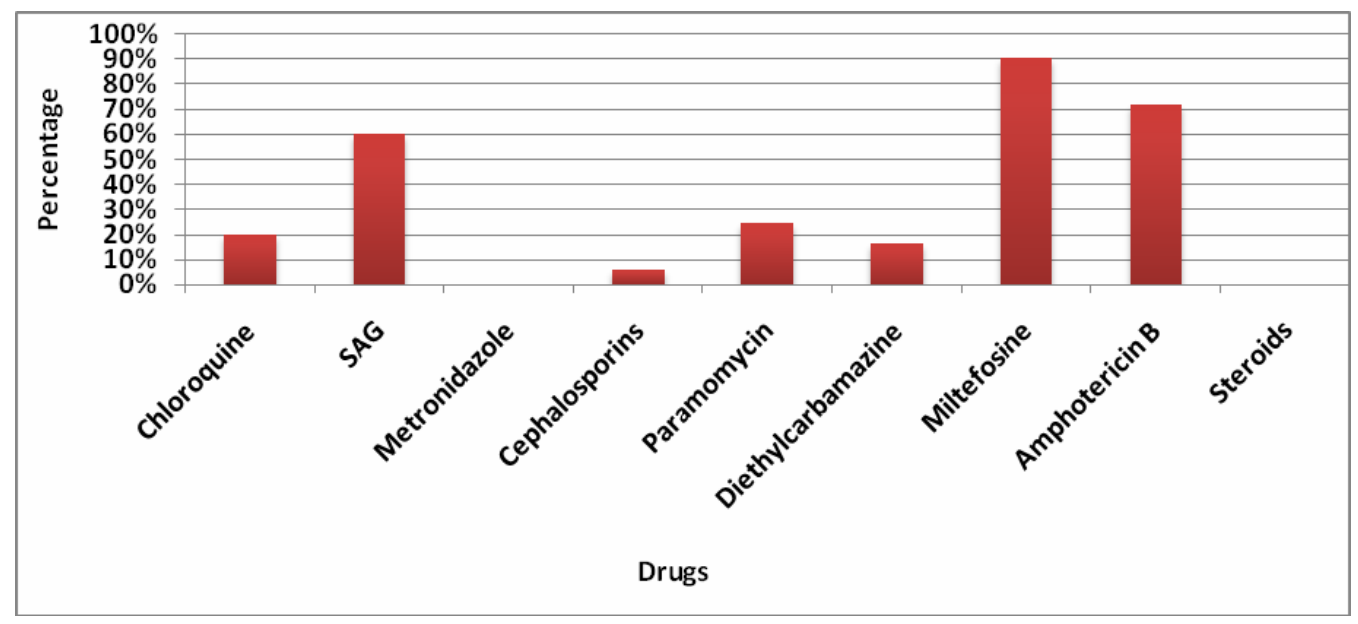

Fig. 5. Knowledge of the professionals about the drugs used for treatment of kala-azar.

Most of the professionals reported pyrexia, spleen enlargement, skin discoloration, anaemia, liver enlargement etc as the most prominent clinical features of kala-azar while the most reported $(86.67 \%)$ clinical feature was 
anaemia and the lowest reported (4.44\%) clinical feature was bloody diarrhoea (Table 9). The present investigation revealed that, about $91.11 \%$ professionals recommended rK 39 dipstick test, $06.67 \%$ had concept about splenic puncture and another $02.22 \%$ professionals believed serological tests as the single most important diagnostic test for visceral leishmaniasis (Table 10). About 90.59\% and $71.76 \%$ of the professionals reported that Miltefosine and Amphotericin B are the drugs that are used for treatment of kala-azar while $60 \%$ of the professionals reported sodium antimony gluconate (SAG) as a drug for treatment of kala-azar patients (Fig. 5).

Table 9. Knowledge of the professionals regarding the clinical features of VL

\begin{tabular}{lcc}
\hline Clinical features & Number (total 45) & Percentage \\
\hline Pyrexia & 33 & 73.33 \\
Abdominal swelling & 11 & 24.44 \\
Weight loss & 19 & 42.22 \\
Anaemia & 39 & 86.67 \\
Spleen enlargement & 32 & 71.11 \\
Liver enlargement & 28 & 62.22 \\
Skin discoloration & 33 & 73.33 \\
Bloody diarrhoea & 5 & 4.44 \\
Lymph node swelling & 18 & 40.00 \\
\hline
\end{tabular}

Table 10. Knowledge of the professionals about the single most important blood test for diagnosis of kala-azar

\begin{tabular}{lcc}
\hline Tests & Number & Percentage \\
\hline Bone marrow examination & - & - \\
rK 39 dipstick test & 41 & 91.11 \\
Direct agglutination test & - & - \\
Splenic puncture & 3 & 06.67 \\
Lymph node biopsy & - & - \\
Serological tests & 1 & 02.22 \\
Total & 45 & 100 \\
\hline
\end{tabular}

So, it is clear that kala-azar is a poverty-related disease. The poor people have not sufficient knowledge about kala-azar agent and it's vector and do not take treatment timely and treatment remain incomplete many times. People affected by VL mostly present to primary health care centers (PHCs), often late in their therapeutic itinerary. PHC physicians face a major challenge. They deal 
with patients presenting with complaints pointing to several diagnostic possibilities. Risk exists when some patients having less clinical manifestations are misdiagnosed. Therefore, field based accurate, sensitive and cost effective rapid diagnostic tools that can detect disease in its mildest form are essential for effective control and reaching the goal of VL elimination.

\section{LITERATURE CITED}

ALVAR, J., YACTAYO, S. and BERN, C. 2006. Leishmaniasis and poverty. Trends in Parasitology. 22(12): 552-557.

Alvar, J., VElEZ, I. D., BERN, C., HERRERO, M., DESJEUX, P., CANO, J., JANNIN, J., DEN BOER, M. and WHO LEISHMANIASIS CONTROL TEAM. 2012. Leishmaniasis worldwide and global estimates of its incidence. PloS one. 7(5): e35671.

BERN, C., and CHOWDHURY, R. 2006. The epidemiology of visceral leishmaniasis in Bangladesh: prospects for improved control. Indian J. Med. Res. 123: 275-288.

CHATTERJEE, K. D. 1995. Parasitology, protozoology and Helminthology. 12th edition. Chatterjee Medical Publishers, Calcutta. pp. 238.

EVANS, T., NAIDU, T.G., DE ALENCAR, J.E. and PEARSON, R.D. 1984. The relationship of American visceral leishmaniasis to ABO blood group type. Am. J. Trop. Med. Hyg. 33(5): 805807.

ICDDR, B. 2003. Centre for health and population research. Health and Science Bulletin 1: 1-6.

KHANUM, H. and AKHTER, S. 2008. Report on KAP survey: A survey to compare knowledge, attitude and practices (KAP) about kala-azar in Bangladesh between endemic areas covered by government interventions vs. areas where interventions are yet to commence. Malaria and Parasitic Disease Control Unit, Directorate General of Health Services, Ministry of Health and Family Welfare, Bangladesh.

KHANUM, H., ZAMAN, S., YESMIN, S., MUSA, S., BANU, H. and ARJU, T. 2015. Knowledge, attitude and practice of inhabitants and professionals for treatment, prevention and control of visceral leishmaniasis in non-endemic districts of Bangladesh. Bangladesh J. Zool. 43(2): 189-199.

LE RUTTE, E. A., COFFEnG, L. E., BONTJE, D. M., HASKER, E. C., POSTIGO, J. A. R., ARGAW, D., BOELAERT, M. C. and DE VLAS, S. J. 2016. Feasibility of eliminating visceral leishmaniasis from the Indian subcontinent: explorations with a set of deterministic age-structured transmission models. Parasites \& Vectors. 9(1): 1-14.

NAZNIN, E. and HOQUE, M. E. 2015. Visceral Leishmaniasis Elimination Program in Bangladesh and Achieving Millennium Development Goal. International journal of tropical disease \& health. 5(1): 30-36.

PARK, J. E. and PARK, K. 1987. Text book of Preventive and Social Medicine. Published by M/S. Banarsidas Bhanot, India 11th edition. 246-248 pp. 
RAHMAN, K. M., ISLAM, S., RAHMAN, M. W., KENAH, E., GALIVE, C. M., ZAHID, M. M., MAGUIRE, J., RAHMAN, M., HAQUE, R., LUBY, S. P. and BERN, C. 2010. Increasing incidence of postkala-azar dermal leishmaniasis in a population-based study in Bangladesh. Clinical Infectious Diseases. 50(1): 73-76.

RANJAN, A., SUR, D., SINGH, V.P., SIDDIQUE, N.A., MANNA, B., LAL, C.S., SINHA, P.K., KISHORE, K. and BHATTACHARYA, S.K. 2005. Risk factors for Indian kala-azar. Am. J. Trop. Med. Hyg. 73(1): 74-78.

THAKUR, C. P. 1984. Epidemiological, Clinical and Therapeutic features of Bihar Kala-azar (including post kala-azar dermal leishmaniasis). Trans. R. Soc. Trop. Med. Hyg. 78: 391-398.

WORLD HEALTH ORGANIZATION. 2015. Kala-Azar elimination programme: Report of a WHO consultation of partners, Geneva, Switzerland.

YARED, S., DERIBE, K., GEBRESElASSIE, A., LEMMA, W., AKILILU, E., KIRSTEIN, O.D., BALKEW, M., WARBURG, A., GEBRE-MICHAEL, T. and HAILU, A. 2014. Risk factors of visceral leishmaniasis: a case control study in north-western Ethiopia. Parasites \& vectors. 7(1): 470.

(Manuscript received on 25 June, 2017; revised on 30 June, 2017) 